\title{
FETAL ANATOMY OF PARATHYROID GLANDS
}

D0I: 10.36740/WLek202001109

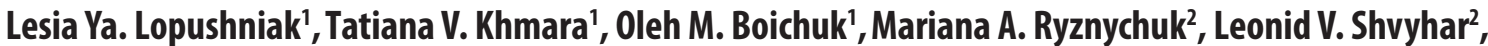 \\ Mariana I. Kryvchanska ${ }^{3}$ \\ 'DEPARTMENT OF HUMAN ANATOMY NAMED AFTER MG TURKEVICH, HIGHER STATE EDUCATIONAL ESTABLISHMENT OF UKRAINE \\ "BUKOVINIAN STATE MEDICAL UNIVERSITY", CHERNIVTSI, UKRAINE \\ 2PEDIATRICS AND MEDICAL GENETICS DEPARTMENT, HIGHER STATE EDUCATIONAL ESTABLISHMENT OF UKRAINE \\ "BUKOVINIAN STATE MEDICAL UNIVERSITY", CHERNIVTSI, UKRAINE \\ ${ }^{3}$ MEDICAL BIOLOGY AND GENETICS DEPARTMENT, HIGHER STATE EDUCATIONAL ESTABLISHMENT OF UKRAINE \\ "BUKOVINIAN STATE MEDICAL UNIVERSITY", CHERNIVTSI, UKRAINE
}

\begin{abstract}
The aim: To study the forms of anatomical variability of the external structure of the upper and lower parathyroid glands in the fetal period of human ontogenesis. Materials and methods: The study involved 48 specimens of human fetuses with $81,0-375,0 \mathrm{~mm}$ of crown-rump length (CRL). The study was conducted by means of macromicroscopic preparation, morphometry and variation statistics method.

Results: The age and individual anatomical variability, complex way of development and formation of synotopic embryotropographic correlations of the upper and lower parathyroid glands in the prenatal period of human ontogenesis create numerous prerequisites for the emergence of variants of their external structure and topography in the fetuses of both different and the same age groups.

Conclusions: There is a significant anatomical variability of the upper and lower parathyroid glands in 4-10-month-old fetuses, which is manifested by varieties of their shape and topical location. Aplasia of the upper parathyroid glands, which was found in two human fetuses aged 7 months, was due to the fetures of their organogenesis and the formation of syntopy in the embryonic and prefetal periods of their development. Parathyroid glands are mainly supplied with blood by the branches of the inferior thyroid artery. The branches of the upper thyroid artery and the arteries of adjacent organs: larynx, trachea and esophagus are involved in the blood supply. The right and left inferior thyroid veins are tributaries of the corresponding brachiocephalic vein, paired (right and left) superior and middle thyroid veins are those for the internal jugular vein.
\end{abstract}

KEY WORDS: parathyroid glands, ontogenesis, anatomical variability

Wiad Lek. 2020;73(1):52-57

\section{INTRODUCTION}

The problem of specific complications in thyroid surgery is very acute in both Ukraine and in the world, which is associated with a large number of operations on the thyroid gland (TG) (in Ukraine there are 11-12 thousand operations per year) and the incessant tendency to increase the incidence of diseases [1]. Among the main specific complications in thyroid surgery (damage to the laryngeal nerve with subsequent paresis of the larynx and hypoparathyroidism with hypocalcemia syndrome), it is the postoperative reduction of parathyroid hormone secretion that is the most common type of undesirable effects of surgery occurring in $20-60 \%$ of patients and which causes significant deterioration in the quality and duration of their life $[2,3,4]$. Therefore, the data on the features of the topographic anatomy of the parathyroid glands (PTG) and possible variants of their structure are important to avoid postoperative hypoparathyroidism $[5,6,7]$.

The identification of PTG during surgical interventions may be complicated due to their small size, number, anatomical variations, close location to important structures and unreliable visualization $[8,9,10]$.
The PTG play an important role in controlling the level of calcium and, therefore, have a direct impact on muscle contraction and neurotransmission. Structural variants and ectopic location of the PTG increase the complexity of surgical interventions on the TG and PTG $[11,12]$.

Heterotopia of the PTG due to aberrant migration in the early stages of development and the impossibility of their identification may lead to errors in surgical interventions on the TG and PTG, in the mediastinum and pericardium area. According to anatomical studies, the incidence of PTG ectopia is about $2-43 \%$ and $14-16 \%$ in patients with primary and secondary hyperparathyroidism, respectively. The ectopic localization of the lower PTG in the anterior mediastinum is most frequently observed, and the most common heterotopia of the upper PTG is the tracheoesophageal groove or the retroesophageal region $[13,14]$.

Finding patterns of the development of the structure and topography of fetal organs and systems is important for the interpretation of the true direction of organogenesis processes, mechanisms of normal body growth, the emergence of anatomical variants and congenital malformations [15]. Studying the shapes of anatomical variability of organs and structures, in 


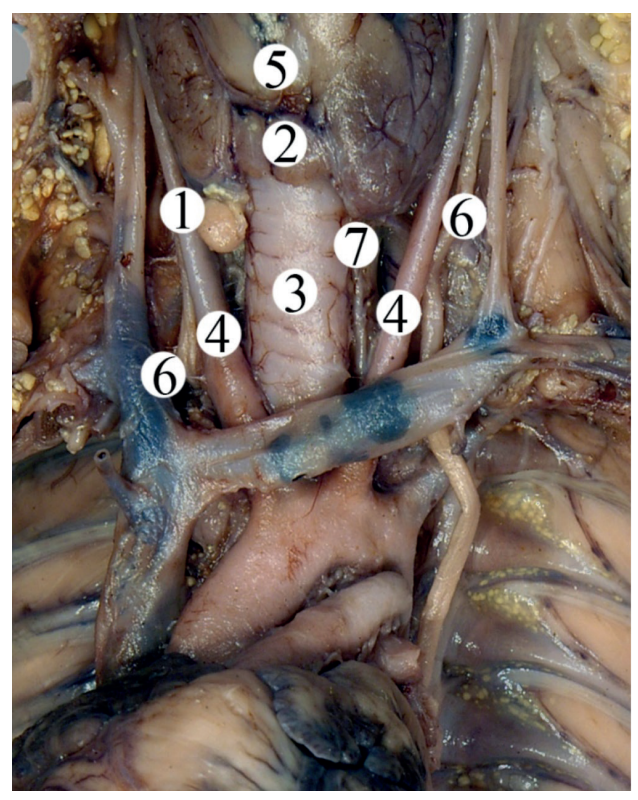

Fig. 1. The organs and structures of the neck and thoracic cavity of the fetus with $170.0 \mathrm{~mm}$ of CRL. Gross specimen. Augm. 2,6x:

1 - the right lower parathyroid gland;

2 - the isthmus of the thyroid gland;

3 - the trachea;

4 - the common carotid arteries;

5 - the arch of the cricoid cartilage;

6 - the vagus nerves;

7 - the left recurrent laryngeal nerve.

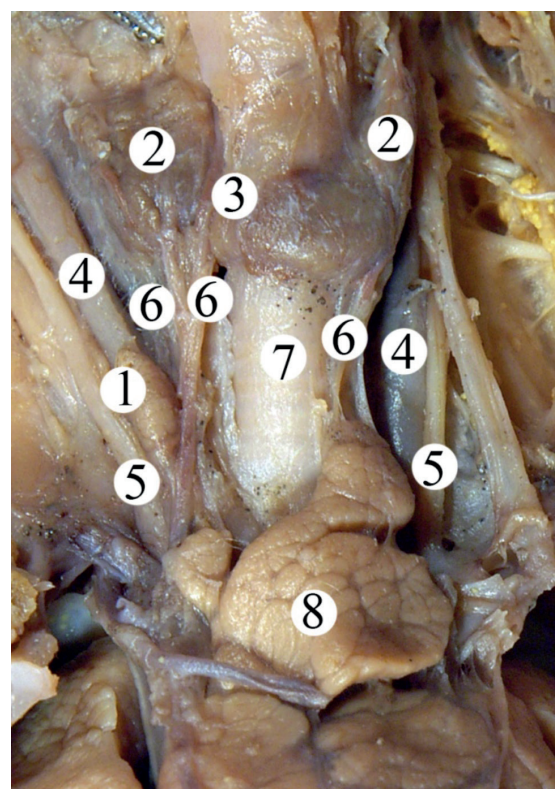

Fig. 2. The organs and structures of the neck and thoracic cavity of the fetus with $190.0 \mathrm{~mm}$ of CRL. Gross specimen. Augm. 2,7x:

1 - the right lower parathyroid gland;

2 - the thyroid gland lobes;

2 - the isthmus of the thyroid gland;

4 - the common carotid arteries;

5 - the vagus nerves;

6 - the inferior thyroid veins;

7 - the trachea;

8 - the thymus.

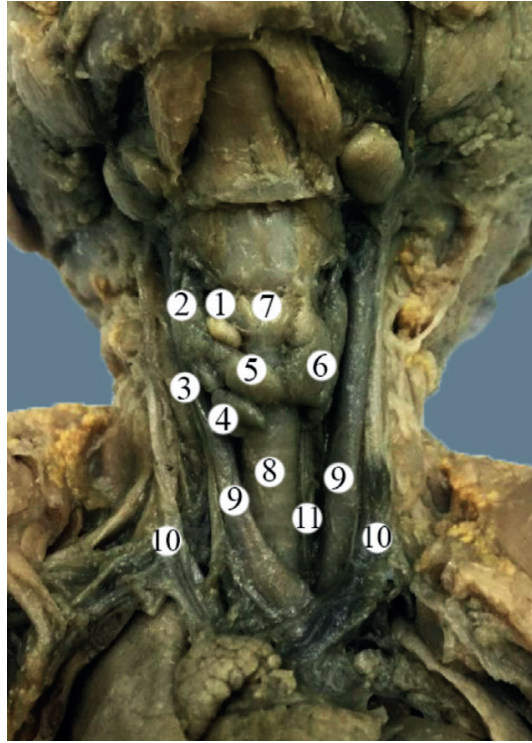

Fig. 3. The organs and structures of the neck and thoracic cavity of the fetus with 192,0 mm of CRL. Gross specimen. Augm. 2,3x:

1 - the right upper parathyroid gland;

2 - the right lateral lobe of the thyroid glandправа;

3 - the right middle lateral lobe of the thyroid gland;

4 - the right lower lateral lobe of the thyroid gland;

5 - the right paramedian lobe of the thyroid gland;

6 - the left lobe of the thyroid gland;

7 - the arch of the cricoid cartilage;

8 - the trachea;

9 - the common carotid arteries;

10 - the internal jugular veins;

11 - the left recurrent laryngeal nerve.

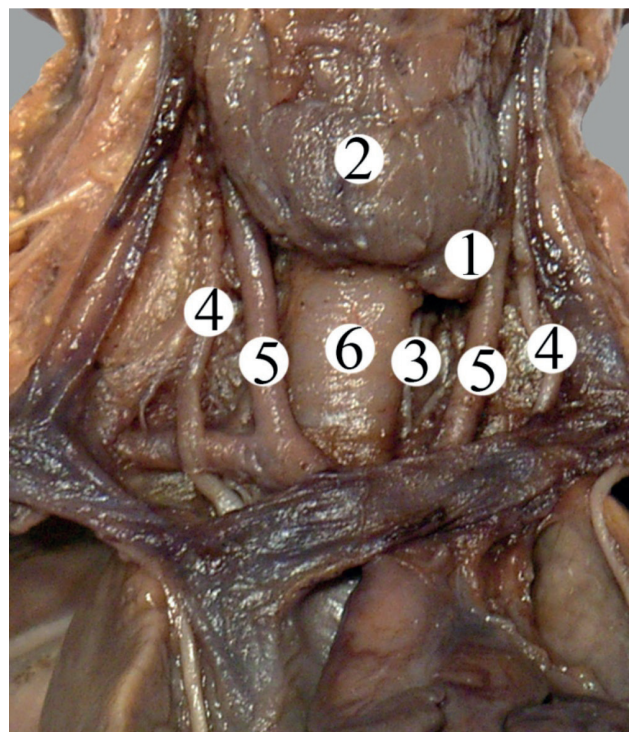

Fig. 4. The organs and structures of the neck and thoracic cavity of the fetus with 225,0 mm of CRL. Gross specimen. Augm. 2,1x:

1 - the left lower parathyroid gland;

2 - the thyroid gland;

3 - the left recurrent laryngeal nerve;

4 - the vagus nerves;

5 - the common carotid arteries;

6 - the trachea. 


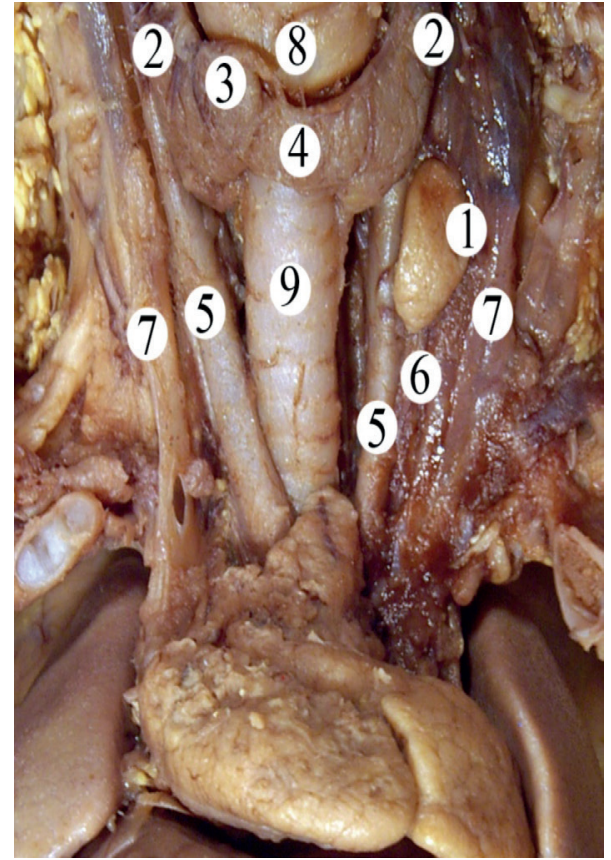

Fig. 5. The organs and structures of the neck and thoracic cavity of the fetus with $240,0 \mathrm{~mm}$ of CRL. Gross specimen. Augm. 1,8x:

1 - the left lower parathyroid gland;

2 - the lobes of the thyroid gland;

3 - the pyramidal process of the thyroid gland;

4 - the thyroid gland isthmus;

5 - the common carotid arteries;

6 - the left vagus nerve;

7 - the internal jugular veins;

8 - the cricoids cartilage arch;

9 - the trachea.

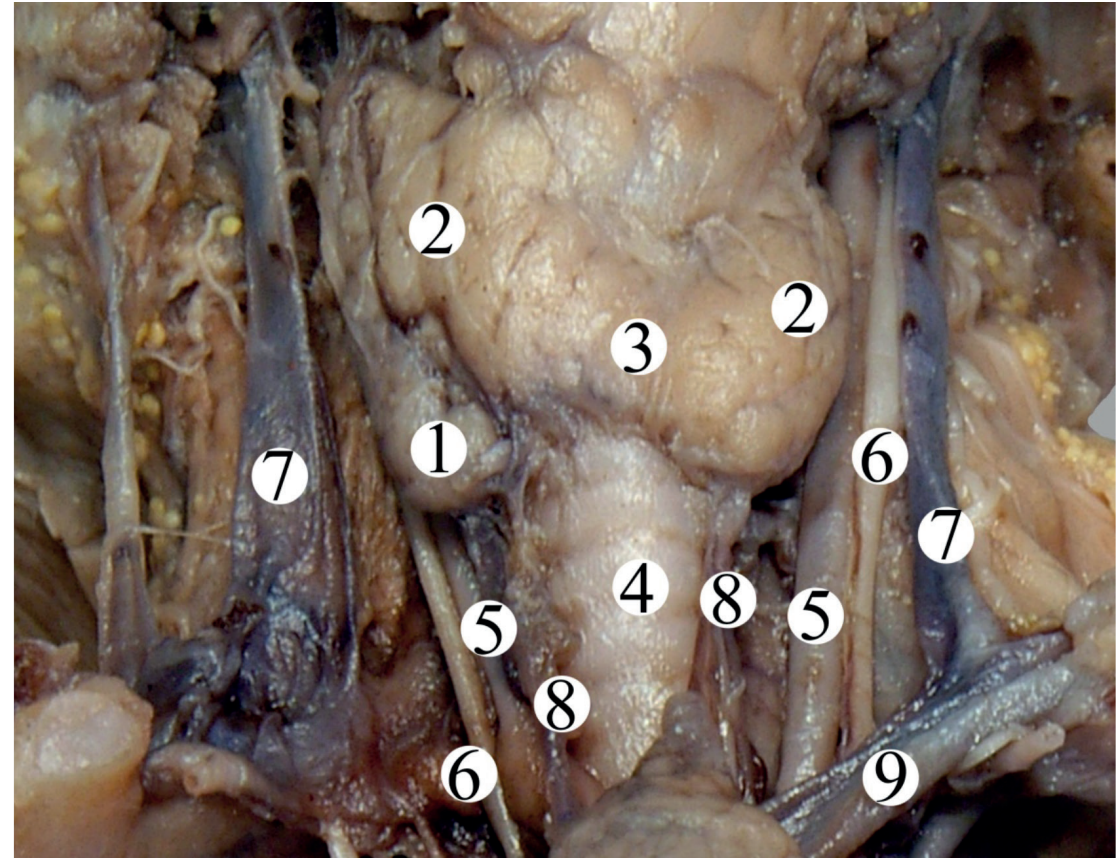

Fig. 6. The organs and structures of the neck and thoracic cavity of the fetus with $280,0 \mathrm{~mm}$ of CRL. Gross specimen. Augm. 2,4x:

1 - the right lower parathyroid gland;

2 - the lobes of the thyroid gland;

3 - the isthmus of the thyroid gland;

4 - the trachea;

5 - the common carotid arteries;

6 - the vagus nerves;

7 - the internal jugular veins;

8 - the lower thyroid veins;

9 - the left brachiocephalic vein. particular the glands of the internal secretion during the fetal period of human ontogenesis is a comprehensive task. The sources of literature contain rare reports on prenatal morphogenesis and variant anatomy of the PTG $[8,16]$, which does not fully reflect their age and individual anatomical variability.

\section{THE AIM}

To study the forms of anatomical variability of the external structure of the upper and lower parathyroid glands in the fetal period of human ontogenesis.

\section{MATERIALS AND METHODS}

The study involved 48 specimens of human fetuses with $81,0-375,0 \mathrm{~mm}$ of crown-rump length (CRL) by using gross and fine dissection and morphometry. The study of fetal spesimens with a mass of $500.0 \mathrm{~g}$ or more was conducted in the Chernivtsi region Communal Medical Establishment «Pathologoanatomical Bureau» in accordance with the cooperation agreement. The study also involved spesimens of fetuses of all ages without external signs of anatomical abnormalities or abnormalities of the cervical and anterior thoracic areas from the Museum of the Department of Human Anatomy named after M.G. Turkevych of HSEI of Ukraine «Bukovinian State Medical University».

The Commission on Biomedical Ethics of Bukovinian State Medical University revealed no moral and legal violations during medical scientific research.

\section{RESULTS AND DISCUSSION}

At the beginning of the fetal period of human ontogenesis, PTG develop intensively. 11 of the examined 4-5-monthold fetuses had the variability of the shape of the right and left upper (UPTG) and lower (LPTG) parathyroid glands. For instance, the elongated shape of UPTG and its variants (elongated-oval, elongated-round, spindle-shaped) was observed in 10 cases (45.5\%), oval shape in 7 observations $(31.8 \%)$ and bean-shaped one in 5 cases $(22,7 \%)$. The following variants of the shape of LPTG were found: round -8 observations $(36.4 \%)$, oval -6 cases $(27.3 \%)$, elongated - $5(22.7 \%)$ and crescent-like one- $3(13.6 \%)$. The UPTG in 4-5 month old fetuses are mainly located at the level of the middle third of the posterior surface of the thyroid gland ( 9 cases, $40.9 \%$ ) or between the upper and 
middle third of the thyroid gland (6 observations, 27.3\%), less frequently - at the level of the upper third of the TG lobes -3 cases $(13.6 \%)$, on the border of the middle and lower third of the thyroid gland -2 observations $(9.1 \%)$ or in the thickness of the thyroid gland - 2 (9.1\%). The right and left LPTG take the following positions: at the level of the lower third of the posterior surface of the thyroid gland ( 8 cases, $36.4 \%$ ), below the TG lobes $-6(27.3 \%)$, on the border of the middle and lower third of the thyroid gland $4(18,2 \%)$, within the limits of the vascular-nerve bundles of the neck - $3(13.6 \%)$ and in the thickness of the thyroid gland - 1 case (4.5\%).

In particular, the fetus with $170.0 \mathrm{~mm}$ CRL had an $\mathrm{H}$-shaped thyroid gland and the right LPTG was located under its lower pole. The latter is rounded, $3.5 \mathrm{~mm}$ high and $4.5 \mathrm{~mm}$ wide, adjacent to the lower end of the right thyroid lobe and is located between the trachea and the right common carotid artery (Fig. 1). The left lobe of the thyroid gland is adjacent to the lateral surface of the trachea, cricoid cartilage, and the lateral surface of the esophagus. The isthmus of the thyroid gland is at the level of the 3rd tracheal cartilage. The topical placement of the right and left UPTG, as well as the left LPTG is without any variant features.

The thyroid gland of a fetus with $190.0 \mathrm{~mm}$ of CRL is characterized by a horseshoe shape. The right LPTG which is oval, $7.0 \mathrm{~mm}$ high and $3.5 \mathrm{~mm}$ wide, is located laterally and $8.0 \mathrm{~mm}$ below the basement of the right lobe of the thyroid gland. The back surface of the right side LPTG is closely adjacent to the right common carotid artery. The right vagus nerve is adjacent to the lateral surface of the LPTG, and the right lower thyroid veins to its paramedian surface. (Fig. 2).

Studying 21 fetuses aged 6-7 months in 2 observations (255.0 and $260.0 \mathrm{~mm}$ of CRL) found aplasia of the right and left UPTG. The fetus with $192.0 \mathrm{~mm}$ of CRL had the atypical asymmetric shape of the thyroid gland, which consisted of 5 lobes: the left one; the right paramedian; the right upper lateral one; the right middle lateral and the right lower lateral ones. The fetus did not have the isthmus of the thyroid gland or the pyramidal lobe either. The right UPTG, which is oval, $5.0 \mathrm{~mm}$ long and $3.5 \mathrm{~mm}$ wide, is located atypically, namely: medially of the right upper lateral lobe of the thyroid gland and slightly above the right paramedian lobe of the thyroid gland. The oblique part of the cricothyroid muscle is located medially to the right UPTG. The back surface of the right HPTG is adjacent to the first tracheal ring (Fig. 3).

6-7 month-old fetuses were found to have the following types of UPTG: oval - 13 cases (34.2\%), elongated - 10 $(26.3 \%)$, rounded - $7(18.4 \%)$, crescent-shaped - $5(13.2$ $\%)$, lentil-shaped $-3(7.9 \%)$. The LPTG is characterized by the variability of the shape as well: rounded $-16(38.1 \%)$, lentil-shaped - $10(23.8 \%)$, bean-shaped - $8(19.1 \%)$, oval - 5 (11.9\%), elongated - 3 (7.1\%). In 6-7 month-old fetuses UPTG are generally localized between the upper and middle third of the posterior surface of the thyroid gland -15 cases $(39.5 \%)$ and at the level of the middle third of the thyroid gland - 11 (28.9\%), less frequently - at the level of the upper third of the thyroid gland -7 (18.4\%) or within the vascular nerve bundles of the neck, more laterally to the thyroid gland lobes - 5(13.2\%). LPTG are topically found within the lower third of the thyroid back surface lobes - 19 observations (45.2\%), below the thyroid gland lobes -11 (26.2\%), on the border of the middle and lower thirds of the thyroid gland lobes $-8(19 \%)$, within the vascular-nerve bundles of the neck $-2(4.8 \%)$ or behind the sternum - 2 (4.8\%). The fetus with $225.0 \mathrm{~mm}$ CRL was found to have an atypical shape of the thyroid gland which looked like the letter «L», represented by a vertical (the right lobe with a pyramidal process) and a horizontal (the isthmus and the left lobe) parts, as well as the position of the left LPTG under the lower pole. The left LPTG is lentil-shaped, 3.0 $\mathrm{mm}$ high and $6.0 \mathrm{~mm}$ wide, adjacent to the lower edge of the left lobe of the thyroid gland and is located between the trachea and the left common carotid artery (Fig. 4). The anterior surface of the left LPTG is closely adjacent to the left recurrent laryngeal nerve.

The fetus with $240.0 \mathrm{~mm}$ of CRL was found to have heterotopia of the left LPTG located in the left neurovascular bundle of the neck, between the left common carotid artery and the left internal jugular vein and is $4.0 \mathrm{~mm}$ below the left lobe of the thyroid gland (Fig. 5). The LPTG is oval and its posterior surface adjoins the anterior surface of the left vagus nerve and the anterior-lateral surface of the left common carotid artery. The left LPTG is $11,0 \mathrm{~mm}$ long and $-5,5 \mathrm{~mm}$ wide. The TG, which is horseshoe-shaped, consists of the right and left lobes, which are located on the anterior surface of the trachea, at the level of I-III tracheal cartilages. A pyramidal process leaves the right lobe of the thyroid gland. It should be noted that the isthmus of the thyroid is below the arch of the cricoid cartilage, while the right lobe and the pyramidal process partly cover the arch of this cartilage. The right common carotid artery closely adjoins the right lobe of the thyroid gland laterally, while the left vagus nerve and the left internal jugular vein are adjacent to the left TG lobe. The thyroid cartilage consists of two quadrilateral, symmetrical plates, the right and the left ones, connected at an obtuse angle.

At the end of the fetal developmental period (16 fetuses aged 8-10 months were studied), there is a variability of the shape and position of the right and left UPTG and LPTG. The following variants of the UPTG shape were observed: oval (13 cases, $40.6 \%)$, rounded $-9(28.1 \%)$, elongated -7 (21.9\%), flat - 2 (6.3\%), droplet-shaped one - 1 (3.1\%). The LPTG are more likely to be rounded - 17 observations (53.1\%) and lentil-like ones - $10(31.3 \%)$; rarely they are elongated $-4(12.5 \%)$ and oval -1 (3.1\%). UPTG are, as a rule, located on the border of the upper and middle third of the posterior surface of the thyroid gland lobes- 12 cases (37.5\%), or at the level of the upper third of the thyroid gland - 11 (34.4\%), rarely - at the level of the middle third of the thyroid gland $4(12,5 \%)$, in the thickness of the thyroid gland $-3(9,4 \%)$ or above the thyroid gland lobes $-2(6,2 \%)$. LPTG are mainly localized at the level of the lower third of the posterior surface of the thyroid gland lobes - 15 observations (46.9\%). One or 
two-sided position of the LPTG under the lower ends of the TG lobes thyroid was found in 7 cases (21.9\%), on the border of the middle and lower thirds of the thyroid gland lobes -4 $(12.5 \%)$, in the thickness of the thyroid gland $-4(12.5 \%)$ and within the corresponding neurovascular bundle of the neck in 2 observations (6.2\%). It should be noted that sometimes one and the same fetus has an asymmetry of the shape of the right and left UPTG and LPTG.

The fetus with $280.0 \mathrm{~mm}$ of CRL was found to have an atypical position of the right LPTG - caudolaterally to the right lobe of the thyroid gland (Fig. 6). The latter is butterfly-shaped. The right LPTG, which is rounded, $5.0 \mathrm{~mm}$ high and $6.5 \mathrm{~mm}$ wide, is placed between the lateral wall of the trachea and the right vagus nerve. The posterior surface of the right LPTG is adjacent to the anterior semicircle of the right common carotid artery.

The blood supply of the PTG is mainly carried out by the branches of the inferior thyroid gland. The branches of the superior thyroid artery and the arteries of the adjacent organs: the larynx, the trachea and the esophagus are involved in the blood supply of the PTG. The thyroid venous plexus is located on the anterior surface of the cervical part of the trachea and thyroid gland, arches of the cricoid cartilage and the plates of the thyroid cartilage. The right and left inferior thyroid veins are tributaries of the corresponding brachiocephalic vein while the paired (right and left) superior and middle thyroid veins are those of the internal jugular vein.

\section{CONCLUSIONS}

1. The age and individual anatomical variability, a difficult way of development and formation of syntopic embryonic tropographic correlations of UPTG and LPTG in the prenatal period of human ontogenesis create numerous prerequisites for the emergence of variants of their external structure and topography in the fetuses of both different and the same age group.

2. 4-10 month-old fetuses are characterized by a significant anatomical variability of UPTG and LPTG which manifests itself by the varieties of their shapes and topical location.

3. The UPTG aplasia, which was found in two human fetuses aged 7 months, is due to the features of their organogenesis and the formation of syntopy in the embryonic and pre-fetal developmental periods.

4. The obtained data on the variant anatomy of the PTG should be taken into account by surgeons-endocrinologists and doctors of ultrasound diagnostics during diagnostic and operative manipulations.

Prospects offurther research. The conducted study on the dynamics of the formation of the shape and size of the PTG in 4-10- month-old fetuses indicates the need to further elucidate their variant anatomy in newborns.

\section{REFERENCES}

1. Sethi N, England RJA. Parathyroid surgery: from inception to the modern day. Br J Hosp Med (Lond). 2017; 78(6): 333-337. doi: 10.12968/ hmed.2017.78.6.333.
2. Arici C, Cheah WK, Ituarte PH. et al. Can localization studies be used to direct focused parathyroid operations? Surgery. 2001; 129: 720-729.

3. Cherenko SM, Larin OS, Sichynava RM et al. Poperedzhennia pooperatsiinoho hipoparatyreozu u tyreoidnii khirurhii za dopomohoiu novoho metodu avtotransplantatsii pryshchytopodibnoi zalozy. [Prevention of postoperative hypoparathyroidism in thyroid surgery using a new method of autotransplantation parathyroid glands]. Clinical endocrinology and endocrine surgery. 2014; 3(48): 3-8. (In Ukrainain).

4. Miller FR. Surgical anatomy of the thyroid and parathyroid glands. Otolaryngol Clin North Am. 2003; 36(1): 1-7.

5. Fancy T, Gallagher D 3rd, Hornig JD. Surgical anatomy of the thyroid and parathyroid glands. Otolaryngol Clin North Am. 2010; 43(2): 221-227. doi: 10.1016/j.otc.2010.01.001.

6. Hojaij F, Vanderlei F, Plopper C et al. Parathyroid gland anatomical distribution and relation to anthropometric and demographic parameters: a cadaveric study. Anat Sci Int. 2011; 86(4): 204-212. doi: 10.1007/s12565-011-0111-0.

7. LoPinto M, Rubio GA, Khan ZF et al. Location of abnormal parathyroid glands: lessons from 810 parathyroidectomies. J Surg Res. 2017; 207: 22-26. doi: 10.1016/j.jss.2016.08.045.

8. Oliinyk Ilu. Morfohenez anatomichnykh variantiv pryshchytopodibnykh zaloz.[Morphogenesis anatomical variants of parathyroid glands] In: Akhtemiichuk YuT, redaktor. Narysy perynatalnoi anatomii. Chernivtsi: BDMU; 2011, p. 284-287. (In Ukrainain).

9. Melo C, Pinheiro S, Carvalho L et al. Identification of parathyroid glands: anatomical study and surgical implications. Surg Radiol Anat. 2015; 37(2): 161-165. doi: 10.1007/s00276-014-1333-3.

10. Ryan JJr, Eisenberg B, Pado KM et al. Efficacy of selective unilateral exploration in hyperparathyroidism based on localization tests. Arch. Surg. 1997; 132: 886-91.

11. Kiviniemi H, Vornanen T, Mäkelä J. Kilpi- ja lisäkilpirauhaskirurgian komplikaatioiden välttäminen - embryologisia ja anatomisia näkökohtia. [Prevention of complications of thyroid and parathyroid surgery]. Duodecim. 2010; 126(3): 269-275. [In Finnish].

12. Mohebati A, Shaha AR. Anatomy of thyroid and parathyroid glands and neurovascular relations. Clin Anat. 2012; 25(1): 19-31. doi: 10.1002/ ca. 21220 .

13. Lappas D, Noussios $G$, Anagnostis $P$ et al. Location, number and morphology of parathyroid glands: results from a large anatomical series. Anat Sci Int. 2012; 87(3): 160-164. doi: 10.1007/s12565-0120142-1.

14. Noussios G, Anagnostis P, Natsis K. Ectopic parathyroid glands and their anatomical, clinical and surgical implications. Exp Clin Endocrinol Diabetes. 2012; 120(10): 604-610. doi: 10.1055/s-0032-1327628.

15. Akhtemiichuk YuT, redaktor. Narysy perynatalnoi anatomii. [Essays perinatal anatomy] Chernivtsi: BDMU; 2011.300 s. (In Ukrainain).

16. Peissig K, Condie BG, Manley NR. Embryology of the Parathyroid Glands. Endocrinol Metab Clin North Am. 2018; 47(4): 733-742. doi: 10.1016/j. ecl.2018.07.002.

The research is a fragment of the planned comprehensive inter-departmental theme of the Department of Human Anatomy named after M.G. Turkevych and Department of Anatomy, Topographic Anatomy and Operative Surgery of the HSEI of Ukraine "Bukovinian State Medical University" «Features of morphogenesis and topography of systems and organs in the pre-and postnatal periods of human ontogenesis», state registration number $0115 \mathrm{U} 002769$. 
ORCID and contributionship:

Lesia Ya. Lopushniak - 0000-0001-8362-406X ${ }^{D}$

Tatiana V. Khmara - 0000-0001-8023-5181 ${ }^{F}$

Oleh M. Boichuk - 0000-0001-7226-0803 ${ }^{B}$

Mariana A. Ryznychuk - 0000-0002-3632-2138 ${ }^{\mathrm{C}}$

Leonid V. Shvyhar - 0000-0002-8566-3959 ${ }^{E}$

Mariana I. Kryvchanska - 0000-0003-3425-8125 ${ }^{A}$

\section{Conflict of interest:}

The Authors declare no conflict of interest

\section{CORRESPONDING AUTHOR}

Tatiana V. Khmara

Department of Human Anatomy named after MG Turkevich

Higher State Educational Establishment of Ukraine

Bukovinian State Medical University

Teatralna sq., 2, 58001, Chernivtsi, Ukraine

e-mail:khmara.tv.6@gmail.com

Received: 07.05.2019

Accepted: 18.11 .2019

A - Work concept and design, B - Data collection and analysis, C - Responsibility for statistical analysis,

D-Writing the article, $\mathbf{E}$ - Critical review, $\mathbf{F}$ - Final approval of the article 